\title{
カタクチイワシの成長に伴う脳䯑道形態の変化
}

\author{
小川良德 \\ (1967 年4月 17 日受理)
}

\section{Morphological Transition of the Brain Components of Anchovy with Their Body-growth}

\author{
Yoshinori OGAWA*
}

\begin{abstract}
The morphological changes of the brain of anchovy were elucidated in connection with its growth and then discussed in relation to the changes of behaviour.

The results obtained are summarized as follows:

1) The three stages may be recognized from the view of morphological changes in each part of the brain,

(a) The 1st stage: "Shirasu" stage, less than $30 \mathrm{~mm}$ in total length, when lobus opticus is exclusively large (and the other parts of the brain are not developed).

(b) The 2nd stage: The stages from $40 \sim 60 \mathrm{~mm}$ in total length when lobus opticus, each part of cerebellum, and saccus vasculosus are of adult type and when schooling behaviour and sight feeding behaviour are developed.

(c) The 3rd stage: The stage over $70 \mathrm{~mm}$ in total length when every part of the brain obtains adult type.

2) Judging from the above mentioned results, there seems to be a close relation between the changes of behaviour of anchovy and morphological ones of its brain, especially distinct in lobus opticus, corpus cerebelli, valvula cerebelli, and saccus vasculosus.
\end{abstract}

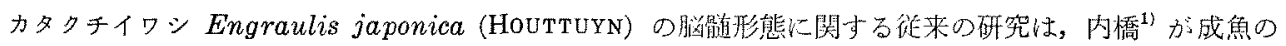
脳形について，京た島村 ${ }^{2 /}$ が Valvula cerebelli の形態について記载しているにすぎない。

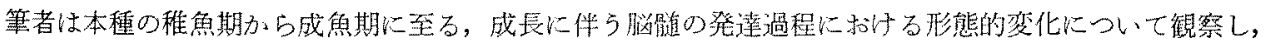
脳形変化と行動変化との関連について若干の考察を試みたのでここに報告する。

本交に先立つて，御指導上御校閲の労を睗つた北海淔大学水産学部教授小林新二期博士，法政大学教授拓 植秀臣博士，瀬戸内海载培漁業協会常務理事内橋潔博士に心からお礼を申しあげる。

\section{材料と方法}

使用摽本は 1953 '66 年の間, 主に石川県七尾湾, 福井県敦賀湾, 兵庫買香住付近, 神奈川県荒崎付近

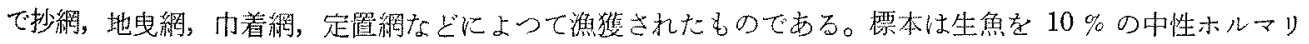
ン液で固定した。

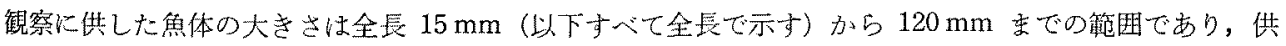
武個体数は同一発育段階個体について，採集年，産地を買にするごとに50尾以上について解剖観察した。 脳娟形態に関寸る観察方法は先に報告しだマイワジの場合と同様である。

脳蹎各部の名称と略号は Table 1 に示寸通りである。

東海区水産研究所業績 B 第 474 号

*矣海区水産研究所 (Tokai Reg. Fish. Res. Lab., Arasaki, Yokosuka, Japan) 
Table 1. Abbreviation for all figures

\begin{tabular}{|c|c|}
\hline 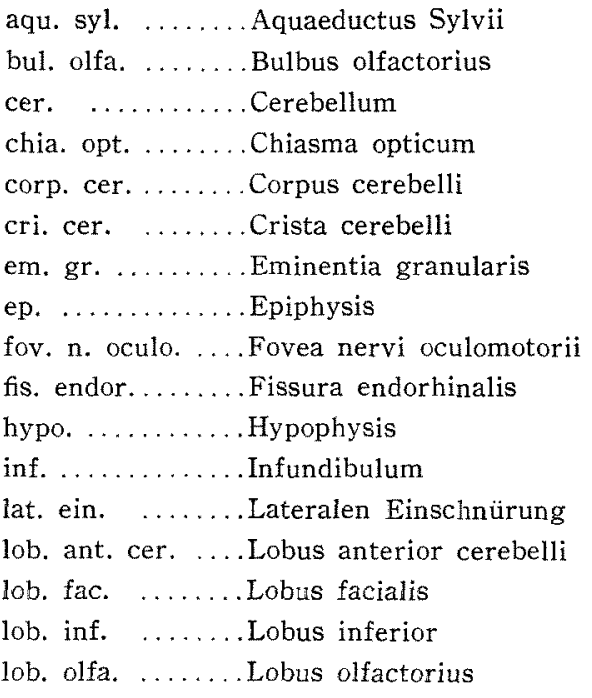 & 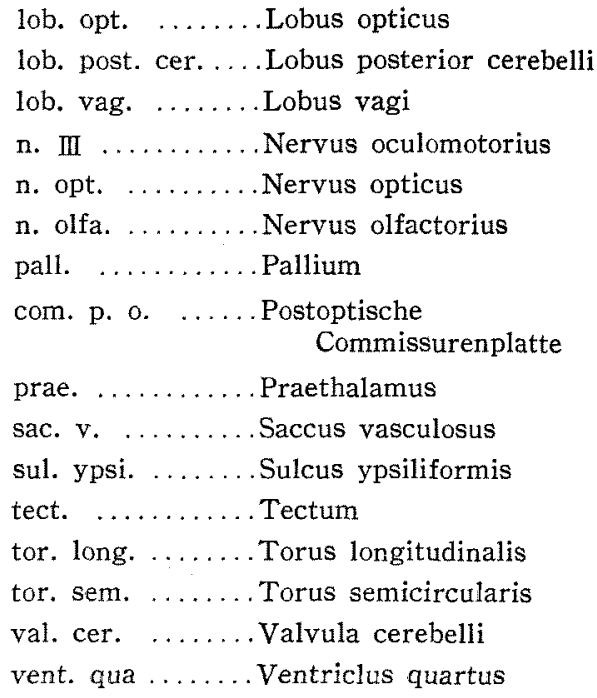 \\
\hline
\end{tabular}

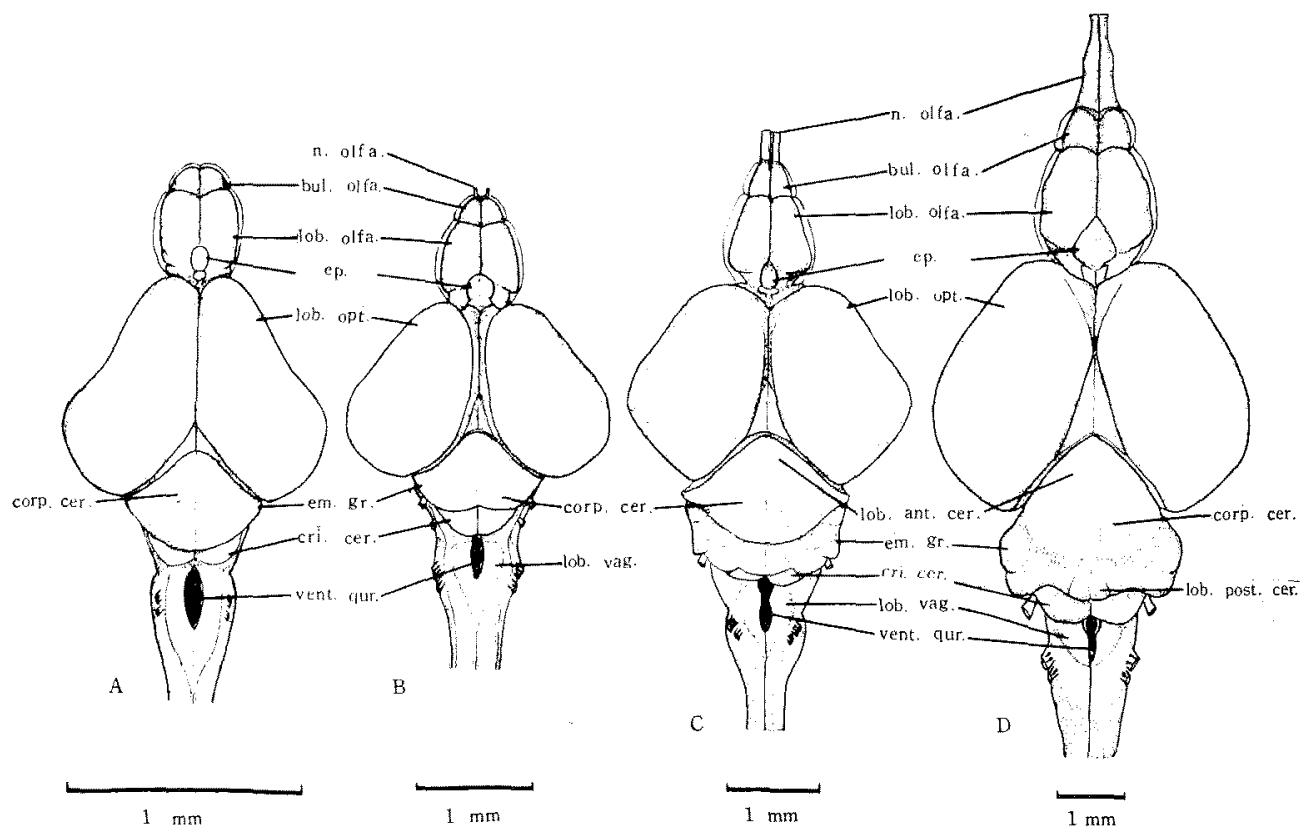

Fig. 1. Dorsal aspects of the brain in Anchovy.
A. Larval stage $15 \mathrm{~mm}$ in total length
B. " $25 \mathrm{~mm}$
C. Young stage $50 \mathrm{~mm}$
D. Adult stage $120 \mathrm{~mm}$ 
結

果

脂肪様物澌カタクチイワシの形態は，きわめて薄い Ossa cranii に㠅われ，Fossa cranii の中に光

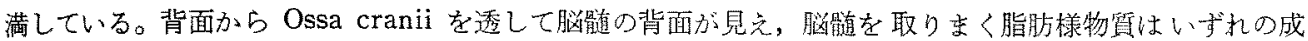
長段階でるきわ的て少ない。

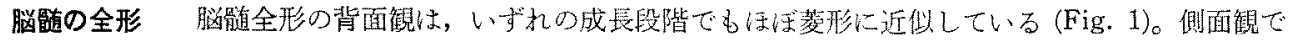

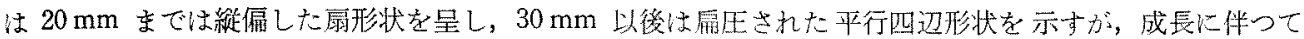
扁王の度合は減少する (Fig. 2)。全体としては稚魚期は栍棒状であるが，成長が進をにつれて檤子状を呈 tे。

n.

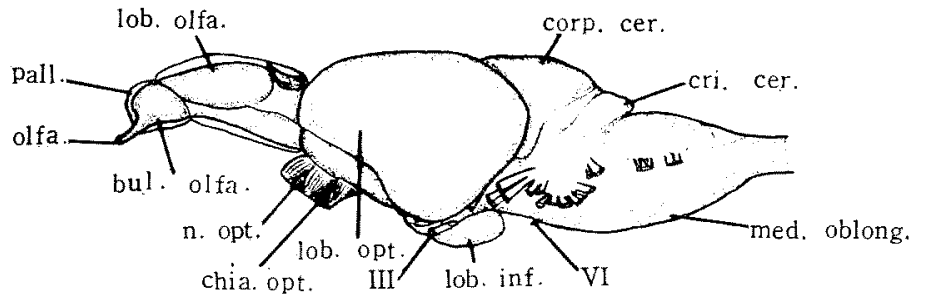

A

$1 \mathrm{~mm}$
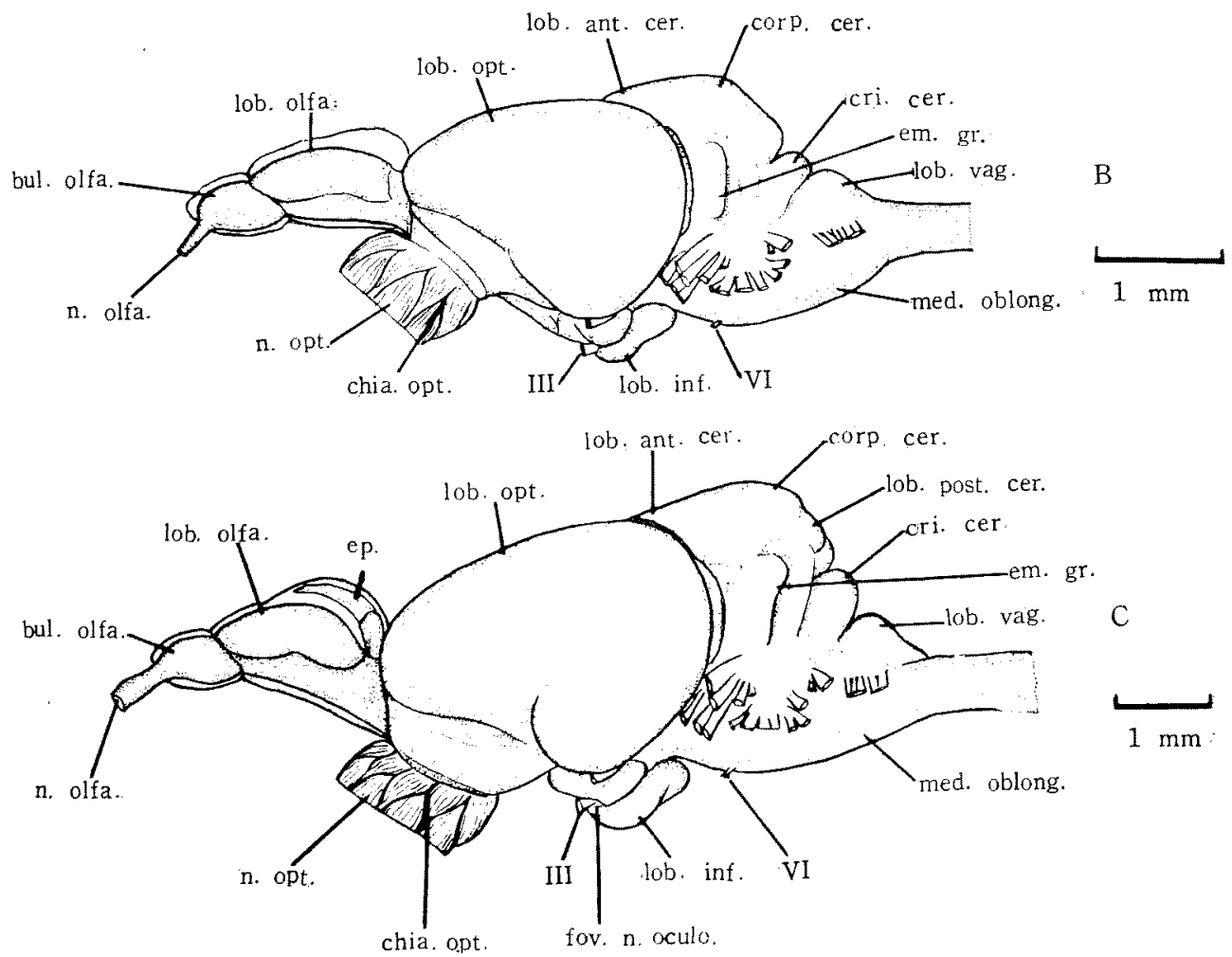

Fig. 2. Lateral aspects of the brain in Anchovy.

A. Larval stage $25 \mathrm{~mm}$ in total length

B. Young stage $50 \mathrm{~mm}$

C. Adult stage $120 \mathrm{~mm}$ 
各脳部の晃かけ上の大きさの順位は Table 2 に示与通りで，Lobus opticus 恬著大で常に第 1 位にある。 Corpus cerebelli の発達によつて 25 60 mm の段階で順位の変化がみられるが，70 $\mathrm{mm}$ 以上での順位は 変化はみられない。

Table 2. The order of the various parts of brain in apparent size

\begin{tabular}{c|c|c|c|c|c}
\hline \hline $\begin{array}{c}\text { Total length } \\
(\mathrm{mm})\end{array}$ & Telencephalon & $\begin{array}{c}\text { Infundibulum } \\
\text { +Lobus inferior }\end{array}$ & Lobus opticus & $\begin{array}{c}\text { Corpus } \\
\text { cerevelli }\end{array}$ & $\begin{array}{c}\text { Medulla } \\
\text { oblongata }\end{array}$ \\
\hline 15 & 3 & 5 & 1 & 4 & 2 \\
20 & 4 & 5 & 1 & 4 & 2 \\
25 & 4 & 5 & 1 & 3 & 2 \\
30 & 5 & $3 \sim 4$ & 1 & $3 \sim 4$ & 2 \\
40 & 5 & 4 & 1 & 3 & 2 \\
50 & 5 & 4 & 1 & 3 & 2 \\
60 & 5 & 4 & 1 & $2 \sim 3$ & $2 \sim 3$ \\
70 & 5 & 4 & 1 & 2 & 3 \\
100 & 5 & 4 & 1 & 2 & 3 \\
\hline
\end{tabular}

Telencephalon Bulbus olfactorius はいずれの成長段階でも Lobus olfactorius よりる小さく， Lobus olfactorius の前方下側に密接している。15 mm で訬背锥は半円形，側面観では三角形状を示す。 $20 \mathrm{~mm}$ 以上の段階では球根状の楕円体となる。

Nervus olfactorius は細く, 稚魚期には短かく，成長に伴って長くなる。その断面は $40 \mathrm{~mm}$ 以前では ほ汪円形であるが，それ以後好棈円形を示す。

Lobus olfactorius は $40 \mathrm{~mm}$ の段階までは，その側面観は長棈円体であり，背面観む棈円形心近似して いるが，後端部に軽微なくびれがみられる。Fissura endorhinalis はこの $40 \mathrm{~mm}$ の段階で浅く認められ る。Lobus olfactorius は $50 \mathrm{~mm}$ の段階に達すると，背面観怙よび側面観ともに棈円形状を示すが，極め て小さく，成魚段階に達しても小さい。Tuberculum taeniae および Sulcus ypsiliformis は判然としな い。

Diencephalon Epiphysis は先端か膨化しておう，10 40 mm の段階では楕円形を示し，50 $\mathrm{mm}$ に 達するとさらに大きく，背面微では丸味を带びた三角形状を呈する。

Nervus opticus は $25 \mathrm{~mm}$ の段階までは極めて細く，40 mm 越兄る段階から急激に丈夫になる。 Infundibulum の直前で左有の神経は交叉する。15 18 $\mathrm{mm}$ の段階では 2 束交互交叉であるが， $25 \mathrm{~mm}$ の 段階から 3〜4 束の交互交叉となる。Nervus opticus は極めて短い。Nervus opticus の断面は $40 \mathrm{~mm} の$ 段階までは扇平であるが，成辰に伴って棈円形となる。

Infundibulum 林 15 40 mm の段階で梳平なは舌状で，Lobus inferior に比較して大きい。その後 端部は叉状を呈している。50 mm を越光る段階から後部が狭小となり，Sulcus recessus hypophysis の周 辺部がいく分膨出する。100 mm を越劣ると Infundibulum は Lobus inferior よりも小さくなる (Fig. 3)。

“Postoptische Commissurenplatte"は外見上認められない。

Lobus inferior $15 \mathrm{~mm}$ の段階では扇正に近いが,この段階で，すでに Fovea nervus oculomotorius

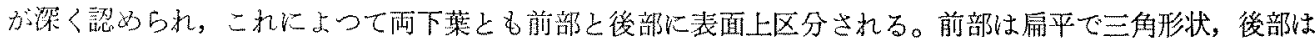
畉円形状を示寸。(Fig. 3-A).

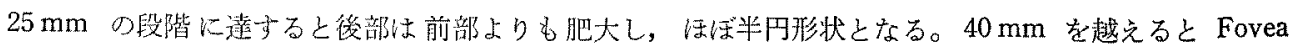
nervus oculomotorius の直後の部分が肥大隆起し，100 mm を越觉るとさらにこの傾向は強化される。

Saccus vasculosus は常に Infundibulum の後端叉状部に位置している。 


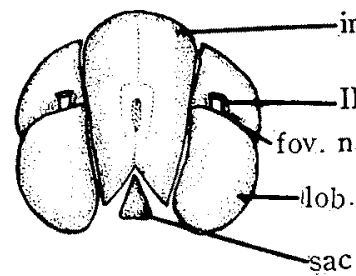

A

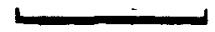

$1 \mathrm{~mm}$

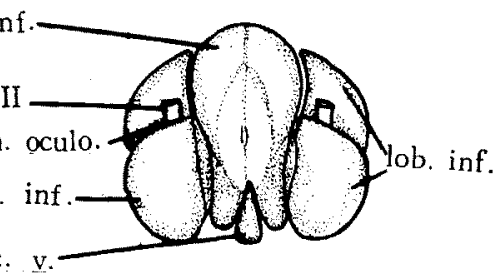

B

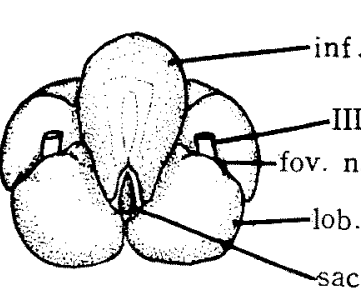

$\mathrm{C}$

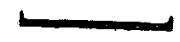

$1 \mathrm{~mm}$

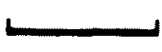

$1 \mathrm{~mm}$

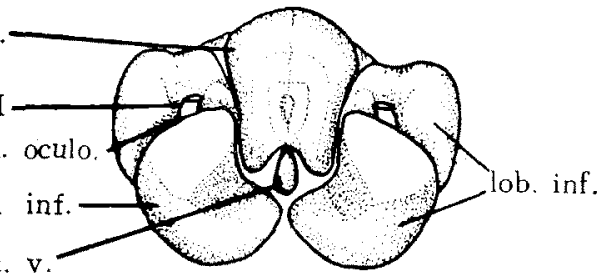

$\mathrm{D}$

Fig. 3. Outline of infundibulum, lobus inferior and saccus vasculosus.
A. Total length $15 \mathrm{~mm}$
B. Total length $25 \mathrm{~mm}$
C. $\quad 50 \mathrm{~mm}$
D.
$120 \mathrm{~mm}$

Infundibulum の後端は成長に伴つて前方に移る。したがつて, Saccus vasculosus 懦下莱の後端より 前方に位置するようになる。Saccus vasculosus の形状は 15〜20 mm の段階では小留形を示すが，成長に 伴つて雨滴形となるが，いずれの成長段階できすかて小さい。

Mesencephalon Lobus opticus 段階での背面観は前部に狭く, 後部は左右に馓開して広く, 側面観では放円形である。20 40 mm では両

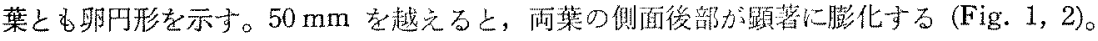

Lobus opticus の側面部には，初期の段階から浅い凹部が認好れ，成長に伴つて明膫となるが，これはマ イワジ認められた“Lateralen Einschnurung”にもたるものと灭られる。

Tectum opticum 老除くと，正中線部分の直下に Torus longitudinalis が前方から後方に向つている。 この Torus longitudinalis は $50 \mathrm{~mm}$ の段階までは細長く, その先端はValvula cerebelli の背面中央部 に達し，它の断面は三角形を示す。成長比伴って，巾広くなり，之の後端は左右に開いている(Fig. 4)。 た Torus semicircularis はいずれの成長段階でる小さい(Fig，4)。

Cerebellum Corpus cerebelli は 15 20 mm ではきわめて未発洼で, Lobus anterior ecrebelli が わずか沉前方へ突出するが，Lobus posterior cerebelli は核とんど認めらない。Corpus cerebelli の背面 観はほほ五角形状を示している。

$25 \mathrm{~mm}$ の段階では Corpus cerebelli の両側が突出する。30 mm に達すると Corpus cerebelli 向に肥大隆起し, Lobus posterior cerebelli がわずかに認められる。またこの段階では Eminentia granularis の直後に小隆起部がみられる。

さらに $40 \mathrm{~mm}$ に達するとCorpus cerebelli の頂部と脚部の境に軽微なくびれが認められ，Lobus pos- 


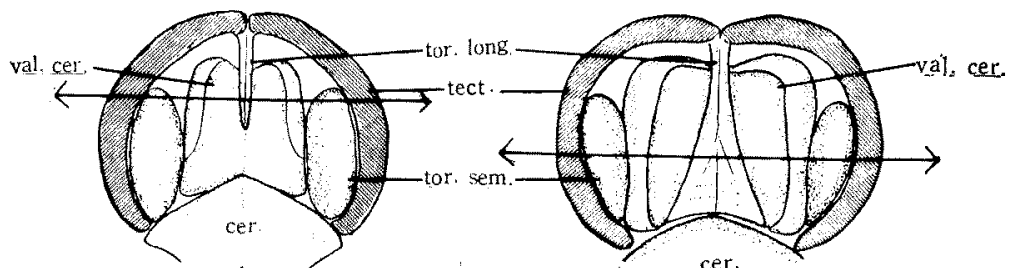

A

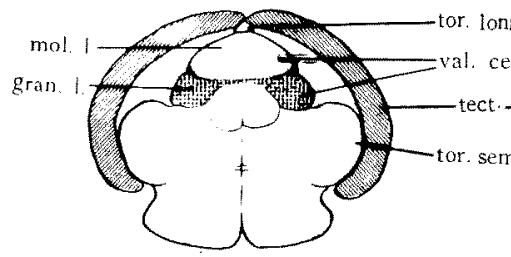

B cer.

C

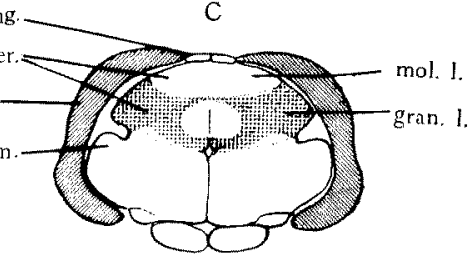

D

Fig. 4. Outline of torus longitudinalis, torus semicircularis, and valvula cerevelli.
A. Total length $30 \mathrm{~mm}$ (Dorsal view)
B.
(Transverse section cutting through the middle
C. Total length $80 \mathrm{~mm}$ segment of the torus longitudinalis)
D. "
(Transverse section cutting through the middle segment of the torus longitudinalis)
(Dorsal view)

terior cerebelli の両側に小棈円形の隆起部が見られるが， $55 \mathrm{~mm}$ に達するとこの隆起部は前述の Eminentia granularis 後方の隆起部と連合して, Lobus posterior cerebelli の側面加ら Corpus cerebelli の 脚部にか壮て明らかな隆起蔽を形成する (Fig. 1)。

Eminentia granularis は $25 \mathrm{~mm}$ の段階昰では小さいが, Corpus cerebelli の発湭とともに肥大し，

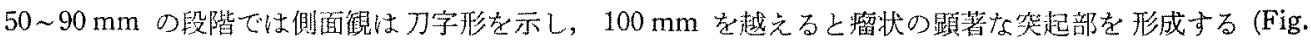
2)。

Valvula cerebelli は $15 \mathrm{~mm}$ では小三角形状の小突起であり，20 mm では添活半円形となる。 $25 \mathrm{~mm}$ では背面観は矩形に近似し，40 50 mm に達するとほぼ四辺形状となつて，中譄腔の大部分占める。

$30 \mathrm{~mm}$ 以後の段階では Valvula cerebelli の先端から傾にか壮て，その外かくをらちどるよらに fissura が認められるが，これ性内部の molecular layer と granular layer の境が裴面に反映しているもの である。

$80 \mathrm{~mm}$ の段階に達すると Valvula cerebelli の後部は左右に膨出展開して軍扇状をなし，90 $\mathrm{mm}$ 以上で ・は中脳腔にほぼ充满する。

Medulla oblongata Crista cerebelli は 15 20 mm では Corpus cerebelli に䍃く単純な小隆起部 にすぎなが，40 mm に達すると肥大して後端部は丸跤を帯びて，左右両葉は相接して Aguaeductus Sylvii 上を渡る。Lobus vagi は Crista cerbelli の後方にやや膨化して喼められる。

\section{考察}

以上脳随各部の形態变化を観察したが，各脳部が成魚形に 達する成長段階についてまとめると Table 3 に示寸通りであり，これから成長段階を第 1 期 $(30 \mathrm{~mm}$ まで)，第 2 期 $(40 \sim 60 \mathrm{~mm})$ ，第 3 期 $(70 \mathrm{~mm}$ 以 上）汇区分することができる。

脳髄の形態からみた第 1 期の特徵は、 Lobus opticus は大きいが, Corpus cerebelli，Valvula cerebelli， 


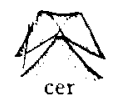

A

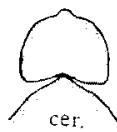

B

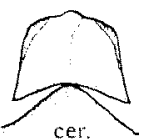

C

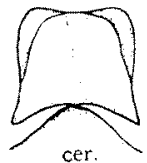

D

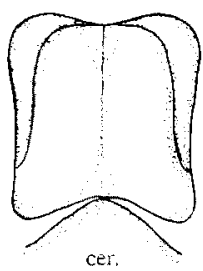

E.

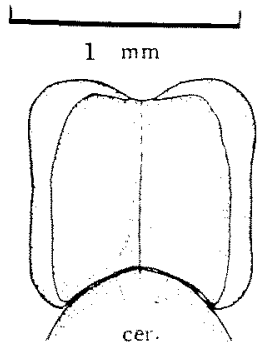

F

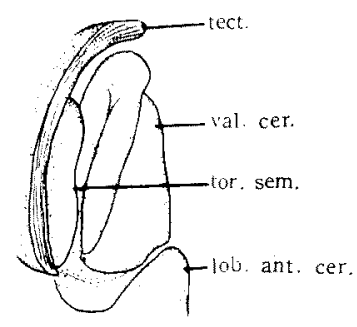

G

Fig. 5. Dorsal view of Valvula cerebelli.
A. Total length $15 \mathrm{~mm}$
E. Total length $35 \mathrm{~mm}$
B. " $20 \mathrm{~mm}$
C. " $25 \mathrm{~mm}$
F. " $50 \mathrm{~mm}$
D. $\quad 30 \mathrm{~mm}$
G. $\quad 50 \mathrm{~mm}$

Table 3. Body size of anchovy when the every part of its brain reaches adult form.

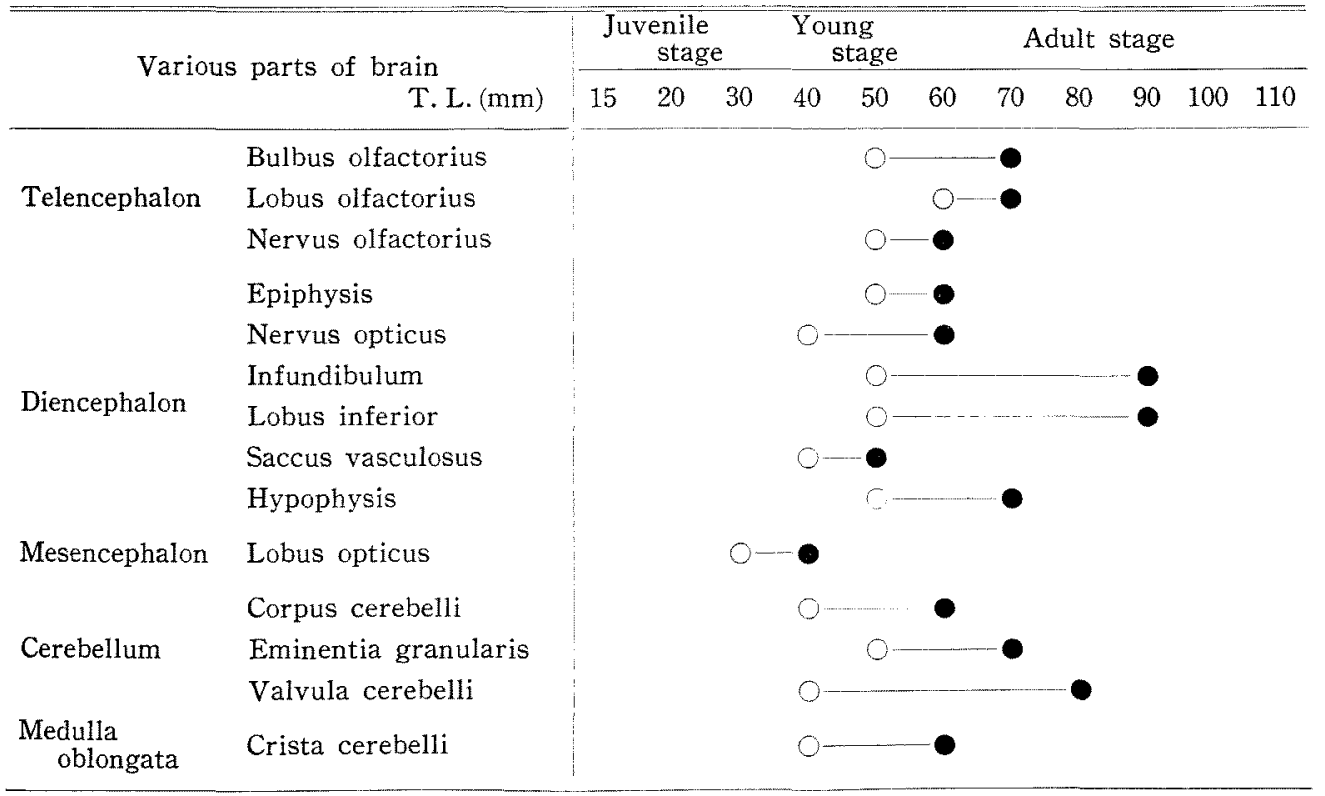

O... semiadult form

.... adult form 
Crista cerebelli などが末発澾である。このことは游泳行動がきかわて緩慢であること, 成群は海流の物理 的条件によって形成されることなどのこととよく符合する。

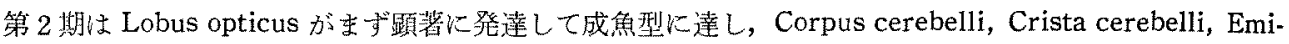
nentia granularis などが発達し, Saccus vasculosus も成魚型飞発澾する。この段階では視覚性の索期行 動となりこれい襄付けである游泳力，钽捷性の增大がるられ，慨料生物る前期上りる大型となる。また前 期の他動的な成群形成から自動的な成群形成がみられるよらになる。Telencephalon は成長に伴つて压と んど発達しない。このことは唤覚の未発達を示すものといえる。

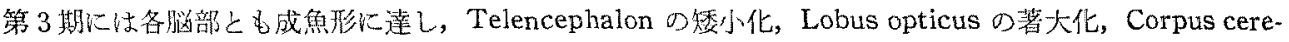
belli, Crista cerebelli 㧍よび Valvula cerebelli の充分な発達がみられる。この段階では本種が毛針で釣

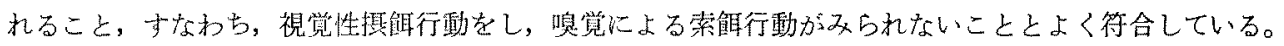

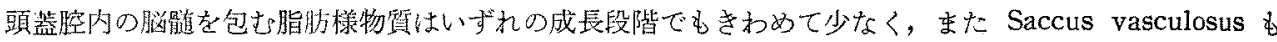
極めて矮小であることは，本種が常に表翼生活者であることと一致している。

要約

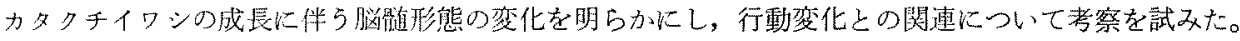
得られた主な結果を要約すると次の通りである。

1. 脳随各部の形態变化から次の三段階丸㭭できる。

(a) 第 1 期： $30 \mathrm{~mm}$ までのシラス期で，Lobus opticus のみ大きく，他の脳部は末発達である。

(b) 第 2 期: 40 60 mm で, Lobus opticus, Cerebellum 各部, Saccus vasculosus なぼが成魚形 となり, 成群行動, 視喾性霖慨行動が発達する。

（c）第 3 期： $70 \mathrm{~mm}$ 以上で，各脳部々も完全成魚型に達する。

2. 以上の結果からカタタチイワシの行動变化と脳䯣形態の変化は密接に関連し, 特に Lobus opticus, Corpus cerebelli, Valvula cerebelli, Saccus vasculosus に上く反映されていることが推察される。

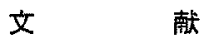

1) 内梪 潔: 日水研赫, 1, 16 (1953).

2) 島村初太郎：日水研報, 12. 18 19 (1963).

3）小川良德：日水研報，4，189 196(1958). 